\title{
Nanopartikül ve Yüzey Pürüzlülüğünün Yapışma Mukavemetine Etkilerinin İncelenmesi
}

\author{
${ }^{1}$ Sinan AYDIN and $* 2$ Ahmet FERTELLI \\ ${ }^{1}$ Faculty of Technology, Department of Mechatronic Engineering Sivas Cumhuriyet University, Turkey \\ ${ }^{* 2}$ Faculty of Engineering, Department of Mechanical Engineering Sivas Cumhuriyet University, Turkey
}

\section{Özet}

Bu çalışmanın amacı, çok duvarlı karbon nanotüp ilave edilmiş epoksi yapıştırıcıda nanotüp oranının ve yüzey pürüzlülüğünün yapışma mukavemetine etkisini tespit etmektir. Bu amaçla,\% 1, \% 1,5 ve \% 2 oranında çok duvarlı karbon nanopartikül katılması durumunda yapıştırıcının yapışma dirençleri deneysel olarak incelenmiştir. Deneysel çalışmalarda çift bileşenli yapıştırıcı (E-350), yüzeyi pürüzlü Alüminyum plaka ve $7 \mathrm{~nm}$ çapında çok duvarlı nanopartikül kullanılmıştır. Pürüzlü yüzeyler için yapışma mukavemetindeki en fazla artış \% 2 nanopartikül oranında, 2,39 Mpa olarak elde edilmiştir.

Anahtar Kelimeler: Epoxy yapıştırıcı, adhezyon testi, çok duvarlı nanopartikül.

\section{Investigation of the Effects of Nanoparticle and Surface Roughness on Adhesion Strength}

The aim of this study is to determine the effects of epoxy with multiwalled carbon nanotubes (MWCNT) reinforced / unreinforced and surface roughness.on the adhesion strength. For this purpose, adhesion strength of adhesive was investigated experimentally when $1 \% \quad 1.5 \% \quad 2 \%$ multiwalled carbon nanoparticles were incorporated into epoxy adhesive. Double-component adhesive (E-350), surface rough aluminum plate and multi-walled nanoparticle with a diameter of $7 \mathrm{~nm}$ were used in the experimental studies. The maximum increases in adhesion strength with $2 \%$ nanoparticle are 2,39 Mpa for rough surface.

Key words: Epoxy adheseve, adhezion pull of test, multiwall carbon nanoparticle

\section{Giriş}

Yapıştırıcılar, en az iki malzemenin birbirine yapıştırılarak birleştirilmesinde istenilen tasarım özelliklerini veren epoksi, fenolik, polyamid, polyimid ve silikon gibi malzemelerin kimyasal olarak birleştirilmesinden oluşan karışımdır [1]. Yapıştırıcı formülasyonlarında kullanılan maddelerin çokluğu ve çeşitliliği değişik özelliklere sahip yapıştırıcıların formüle edilmesini sağlamakta ve ayrıca yapıştııcıların sınıflandırılmasını zorlaştırmaktadır. Buna rağmen, yapıştırıcının seçimini ve kullanımını kolaylaştırmak maksadıyla çeşitli sınıflandırmalar yapılmaktadır. Günümüzde kullanılan modern yapıştırıcılar, kimyasal tipleri ve formları açısından iki ana grup olarak sınıflandırılmaktadır. Kimyasal reaksiyon sertleşen yapıştırıcılar en güçlü yapıştırıcılardır. Bu tip yapıştırıcılara, yapısal yapış̧ırıcılar da denir. Yapısal yapış̧ırıcılar, yük taşıyabilen, esnek, 1sıya dayanıklı yüksek kayma mukavemetine sahip yapıştırıcılardır. Yapısal

*Corresponding author: Address: Faculty of Engineering, Department of Mechanical Engineering Sivas Cumhuriyet University, 58140, Sivas TURKEY. E-mail address: fertelli@cumhuriyet.edu.tr, Phone: +903462191010 
yapıştırıcılar, uzay sanayi, otomotiv endüstrisi, gemicilik vb. birçok alanda sıklıkla kullanılmaktadir [1].

Hong-Yuan ve ark. [2], silika nano parçacıklar ve kauçuk nano parçacıkların epoksi yapıştırıcıya eklenmesi ile kırılma testi sonucunda kırılma tokluğunda ve elastiklik (young) modülündeki değişimleri incelemişlerdir. Çalışmalarında silika nano parçacıkların elastiklik modülünün ve kırılma dayanımının artmasına sebep olduğunu, kauçuk nano parçacıkların ise kırılma tokluğunda ciddi bir artış sağlarken elastiklik modülünün düşmesine sebep olduğunu belirtmişlerdir. Kırılma tokluğundaki artışın sebebini çatlak büyümesi sırasında bağımsız hareket ederek kompozitin dayanıklı̆̆ına katkıda bulunmaları olarak açıklamışlardır. Chena ve ar. [3] karbon nanotüp ile güçlendirilmiş epoksi reçine kompozitlerin tribolojik özelliklerine dispersiyon yönteminin etkilerini araştırmışlardır. Çalışmalarında çift asimetrik santrifüj, sonikasyon ve elle karıştırma yöntemlerini kullanarak karşılaştırma yapmışlardır. Ön işlem görmüş parçacıkların sonikatör kullanıldığında aşınarak hasar gördüklerini bu yüzden bu tipteki parçacıklarda sonikatör kullanılmamasını belirtmişlerdir. Çift asimetrik santrifüjün verimli bir şekilde epoksi reçinesi içindeki CNT'leri dağıttığını ürettiği yüksek kesme gerilmesi sayesinde aglomeraları parçalara ayırmak için etkili bir yol olduğunu ifade etmişlerdir. Delale ve arkadaşları [4], kapalı form çözümü ile kullandıkları yapıştırıcıyı non- lineer özellikte, yapıştırma bölgesinin boyutlarının diğer yan boyutlara göre küçük olduğunu ve yapıştırılan malzemenin kalınlığının sabit olduğunu kabul etmişlerdir. Düzlem şekil değiştirme durumu ile yapıştırılan iki farklı malzemenin gerilme durumlarını araştırmışlardır. Sawyer ve Cooper [5], yapıştırılan malzemelerin kuvvet uygulandığı zaman deforme olduklarını ifade ederek bağlantıda oluşan eğilme momentinin uygulanan yüke bağlı olması sebebiyle yapıştırıcı bağlantısının non-lineer özelliğe sahip olduğunu belirtmişlerdir. $\mathrm{Bu}$ sebeple önce lineer bir çözüm oluşturarak lineer olmayan bir çözüm yöntemine yaklaşım yapmışlardır. Apalak ve arkadaşları [6], sonlu elemanlar yöntemini kullanarak yaptıkları bir çalışmada yapıştırıcıyı lineer elastik bir malzeme kabul ederek yapıştırıcı ile oluşturulmuş köşe bağlantılarında gerilme analizi yapmışlardır. Bağlantının dayanımına kullanılan malzemelerin etkileri ve köşe bağlantısının etkisini araştırmışlardır. Aydın ve arkadaşları [7], basit tekli bindirme bağlantısında geometrik olarak yapıştırılan malzemeler ve kullanılan yapıştırıcının lineer olmayan malzeme davranışlarını dikkate alarak gerilme analizi yapmışlardır. Bağlantıların yüzeylerinde iki farklı hasar tipinin ortaya çıktığını ifade etmişlerdir. Yapıştırıcı tabakasının serbest uçlarında oluşan hasara, çekme etkisiyle soyulma gerilmesinin sebep olduğunu, kayma gerilmesinin etkisi ile bindirme bölgesinin merkezinde ise yıkıcı bir hasar oluştuğunu belirtmişlerdir.

\section{Materyal ve Yöntem}

Bu çalışmada, zımparasız ve zımparalı yüzeyler için çift bileşenli yapıştırıcı ve çok duvarlı karbon nanopartiküllü yapıştırıcı kullanılması durumunda yapışma mukavemetleri incelenmiştir. İlk olarak hem alüminyum levha hem de dolly zımparasız yapıştırılmış, daha sonra sadece levha C180 kumlu silikon karpit ince zımpara ile zımparalanmış ve son olarak her iki parça da zımparalanarak deneyler yapılmıştır.

Yapıştırıcı olarak Akfix E350 çift komponentli, solvent içermeyen, hızlı kürleşen ve aşırı derecede güçlü ve yüksek mukavemetli epoksi bazlı bir metal yapıştırıcı kullanılmıştır. Bu yapıştırıcı boşluk doldurma özelliği sayesinde pürüzlü ve hatta tam olarak uyuşmayan yüzeylerde dahi 
kullanılabilmektedir. Şekil 1'de görüldüğü gibi, yapıştırılan malzeme olarak, çekme dayanımı 145$185 \mathrm{~N} / \mathrm{mm}^{2}$, akma dayanımı $110 \mathrm{~N} / \mathrm{mm}$ olan 5005 alaşımında, H14/H24 sertliğinde ve $40 \mathrm{~mm} \mathrm{x}$ 40mm x $3 \mathrm{~mm}$ boyutlarında eloksallık alüminyum levha kullanılmıştır.

Çok duvarlı karbon nanotüpler Nanografi (Türkiye) firmasından satın alınmış olup, Özellikleri: Siyah renkte, ortalama çapı: $7 \mathrm{~nm}$, boyu: 10-35 $\mu \mathrm{m}$, özgül yüzey alanı: $510 \mathrm{~m}^{2} / \mathrm{g}$, saflığı: ağırlıkça $>$ \% 95 dir. Yapıştırılacak Alüminyum levha ve dolly için yapıştırma işleminden önce yüzey hazırlık ve temizleme işlemleri uygulanmıştır. İlk olarak alüminyum levha yüzeyi C-180 kumlu silikon karpit ince zımpara ile pürüzlendirilmiş ve daha sonra deney numuneleri, üzerinde bulunan kir, yağ ve toz vs. gibi yabancı maddelerin temizlenmesi için aseton ile yıkama ve durulama yapılmıştır. Bu işlemin ardından en son olarak etüv içerisinde $50^{\circ} \mathrm{C}$ de 30 dakika kurutma işlemi yapılarak levhalar yapıştırma işlemine hazır hale gelmiştir.

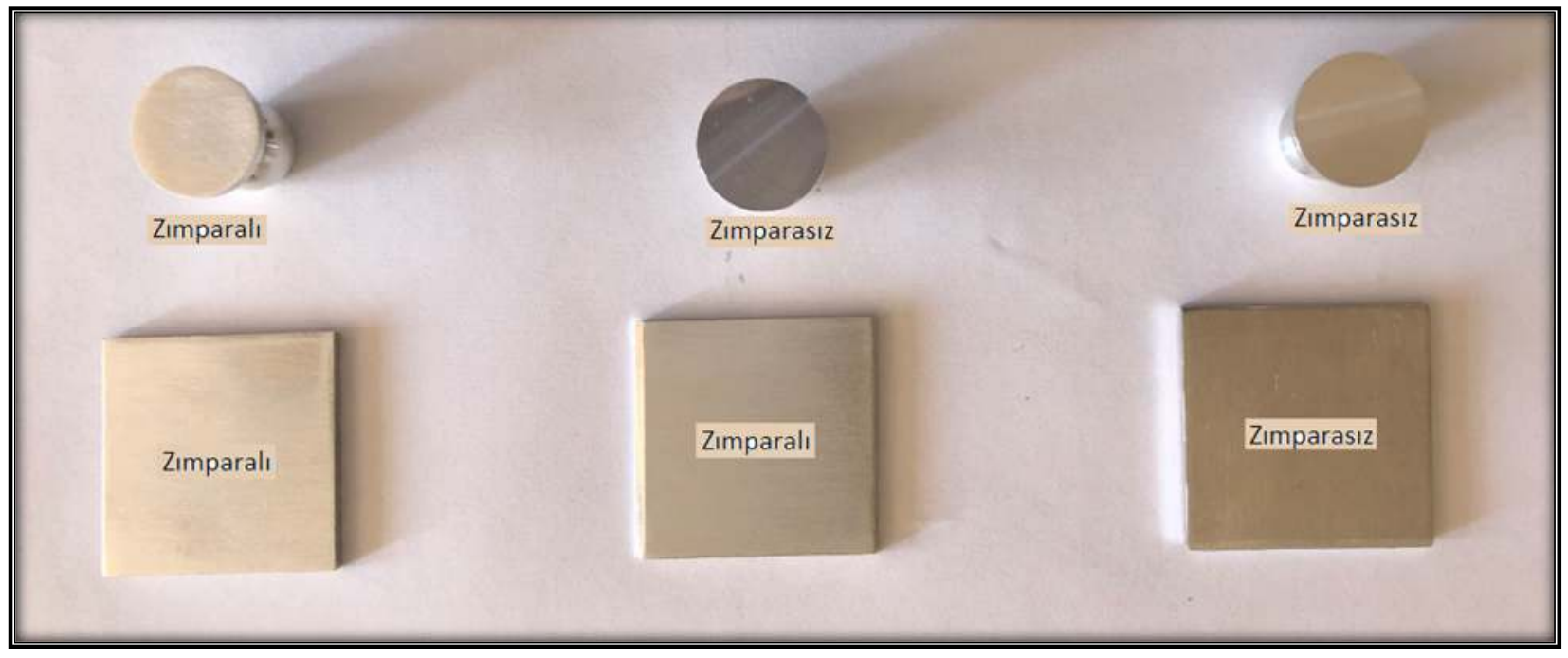

Şekil 1. Alüminyum plaka ve dolly malzemesi

Yapıştırıcıların içerisine nanopartikül katarak hazırlanması için, ağırlıkça \%1, \%1,5 ve \%2 oranında olan çok duvarlı nanopartiküller temiz beher içerisinde bulunan epoksi üzerine eklenmiştir. Epoksi miktarının iki katı kadar aseton, karışımın içerisine eklenerek ultrasonik karıştırıcıda $30 \mathrm{KHz}$ frekansta 10 dakika karıştırma yapılmıştır. Daha sonra karışım, içindeki asetonun buharlaşması için $30^{\circ} \mathrm{C}$ etüv içerisinde bekletildikten sonra epoksi+ nanopartikül karışımı üzerine epoksi sertleştirici eklenerek mekanik karıştırıcıda 5 dakika düşük devirde karıştırma işlemi yapılmıştır. Yapıştırma direnci, ASTM D 4541 ve ISO 4624 standartlarına göre Positest Pull off adhezyon cihazı (Şekil 2) ile adhezyon testlerinin yapılmasıyla ölçülmüşsür. Her yapıştırıcı karışımında (\%1, \%1,5 ve \%2) ortalama bir değer elde edebilmek için 5 adet numune teste tabi tutulmuştur. 


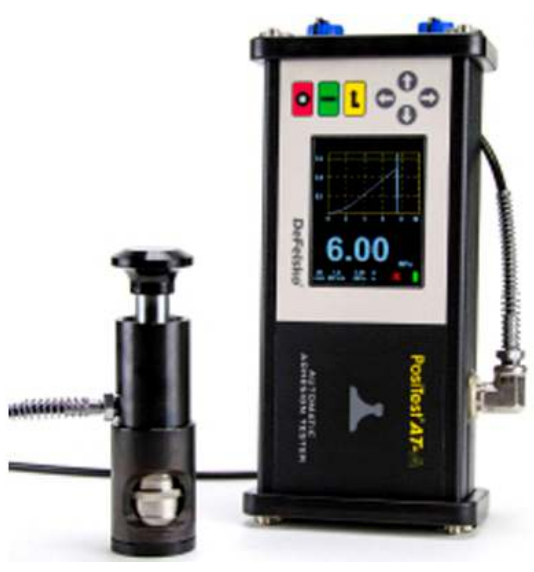

Şekil 2. Adhezyon Pull off test cihazı

\section{Bulgular ve Tartışma}

Şekil 3'de yapıştırıcının dolly üzerindeki SEM görüntülerinden tüm oranlar için (\% 1, \% 1,5 ve \% 2), nanopartiküllerin yapıştırıcı içerisinde homojen dağıldığı görülmektedir. Gerek SEM görüntülerinden gerekse Alüminyum levha ve dolly üzerindeki yapışma yüzeylerinden (Şekil 4), adhezyon hasarının değil, kohezyon hasarının oluştuğu görülmektedir. Bunun sebebi E-350 çelik yapıştırıcısındaki nanopartiküllerin yeni oluşturduğu kimyasal bağlar ile daha güçlü yapışma özelliğine sahip olmasından kaynaklanmaktadır.
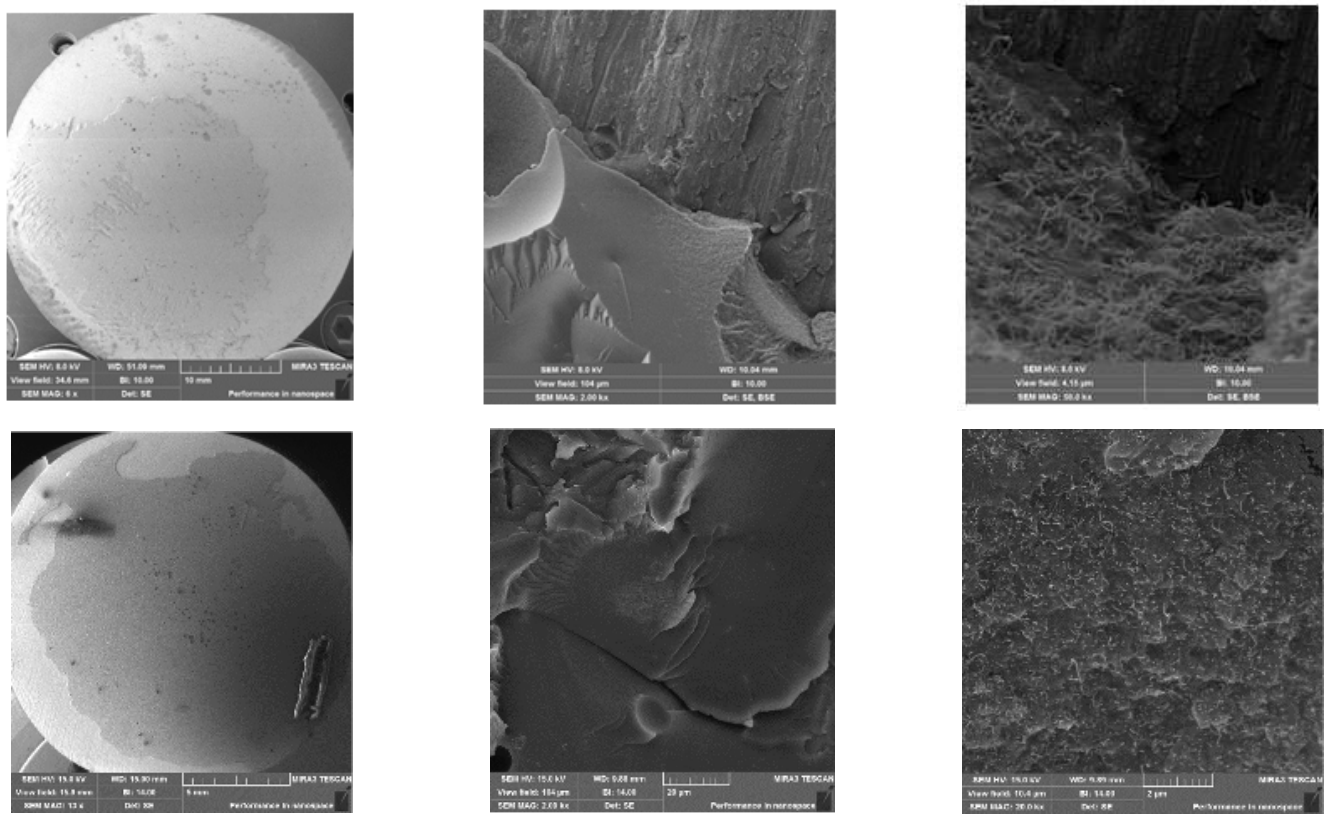

Şekil 3. Dolly üzerindeki homojen dağıtılmış nano partiküllerin SEM görüntüleri 
Şekil 4'den de görüldüğü gibi hem yüzeylerin pürüzlendirilmesi hem de nanopartikül oranlarının artırılması ile kopma sonucu dolly üzerinde kalan yapıştırıcı miktarının da artmaktadır. Yapışıtırıcı miktarındaki bu artış aynı zamanda mukavemetteki artış ile doğru orantılıdır.

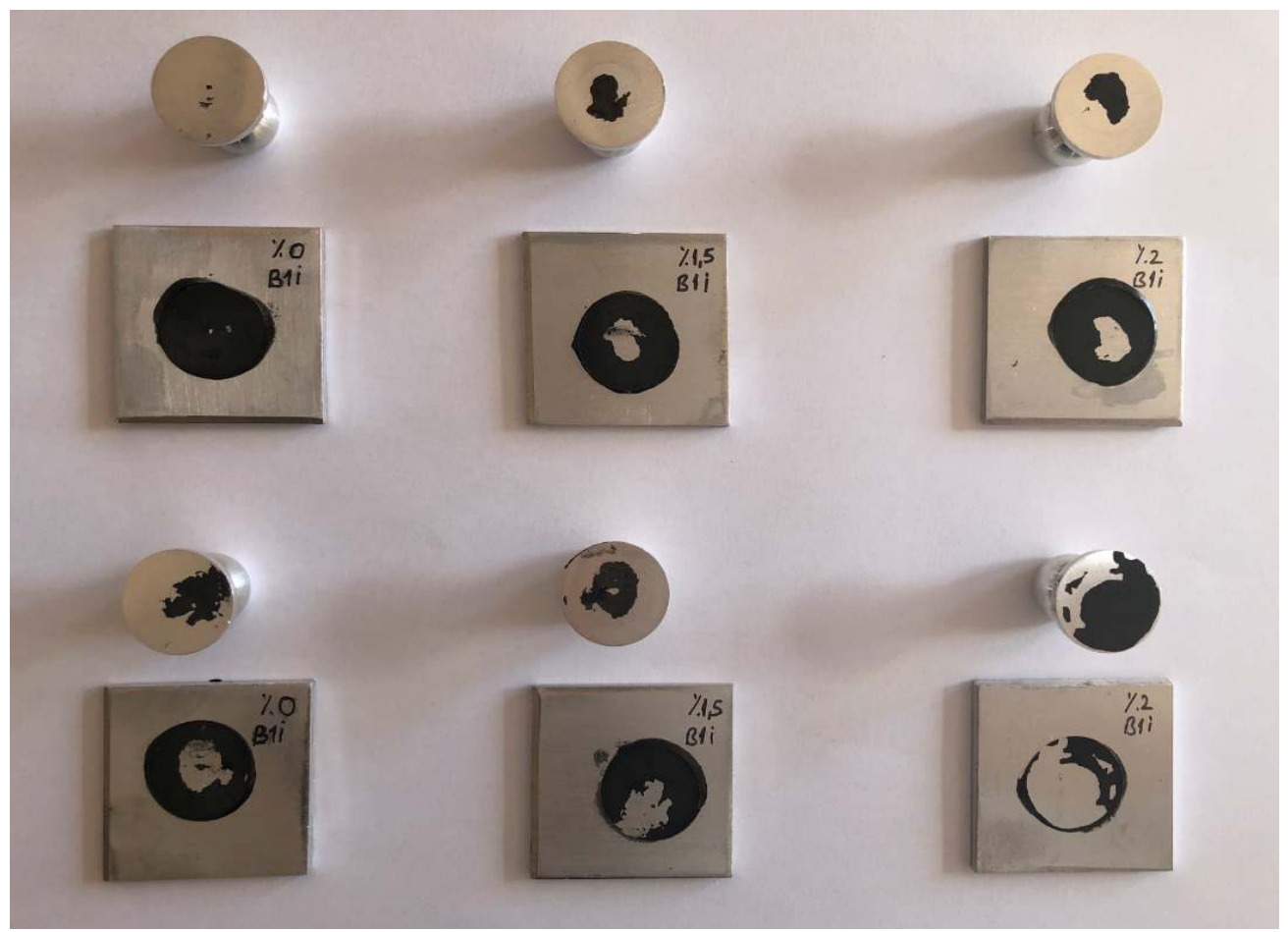

a)

b)

c)

Şekil 4. Farklı katkı oranlarındaki yapıştırıcının dolly ve levha üzerindeki görüntüleri a) $\% 0$ b) $\% 1,5$ c) $\% 2$

Şekil 5'de her iki yüzeyin pürüzsüz olması, sadece Al levhanın zımparalanması ve her iki yüzeyin de zımparalanması durumu için hem katkısız hem de nanopartikül katkılı yapıştırıcı kullanılması durumunda yapışma mukavemeti değişimleri gösterilmektedir. Hiçbir nanopartikül eklenmeden saf yapıştırıcı kullanılması durumunda yapışma mukavemeti zımprasız yüzeyde 1,12 MPa, zımparalanmış levha için 1,66 MPa ve her iki malzemenin de zımparalanması durumunda 1,97 MPa olarak elde edilmektedir. Yüzeyin pürüzlendirilmesi, moleküller arası çekim kuvvetlerini artırmıştır. Epoksi yapıştırıcı içerisine nano parçacıkların \% 1'den \% 2'ye kadar 3 farklı oranda katılmasıyla, tüm farklı yüzeylerde bağlantı mukavemetinin arttığı görülmektedir. Pürüzsüz yüzeyde yapışma mukavemeti 1,12MPa'dan 1,52 MPa'a kadar artarken, tüm yüzeylerin zınparalandığı durumda 1,97 MPa'dan 2,39 $\mathrm{MPa}$ değerine kadar artmıştır. Yüzey pürüzlüğü yapıştırıcının tutunmasını sağlayarak yapıştıııcı ve yapıştırılan malzemeler arasında kilitlenmeyi sağlamakta, nano parçacıklar ise yapıştırıcı molekülleri arasında ve yapışan yüzeyler arasında temas yüzeyinin artmasına imkân sağlayarak bağlantının mukavemetinin artmasına sebep olmaktadır. 


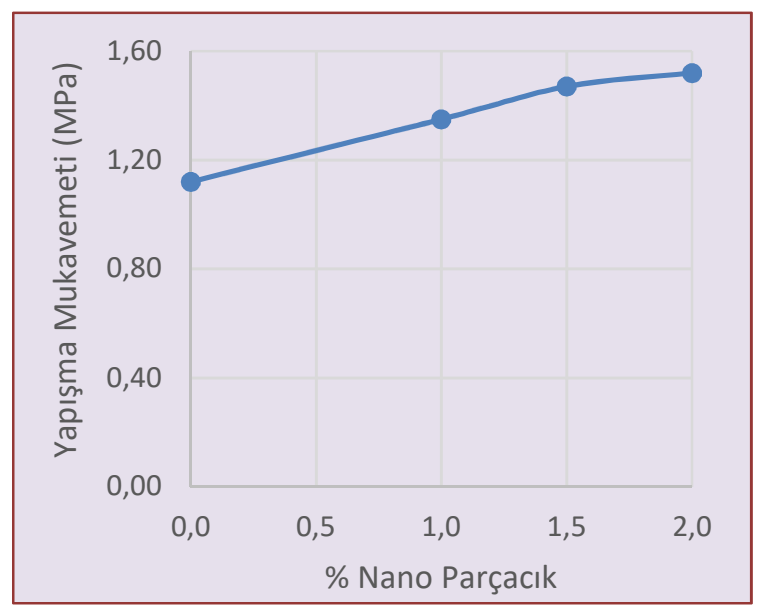

a)

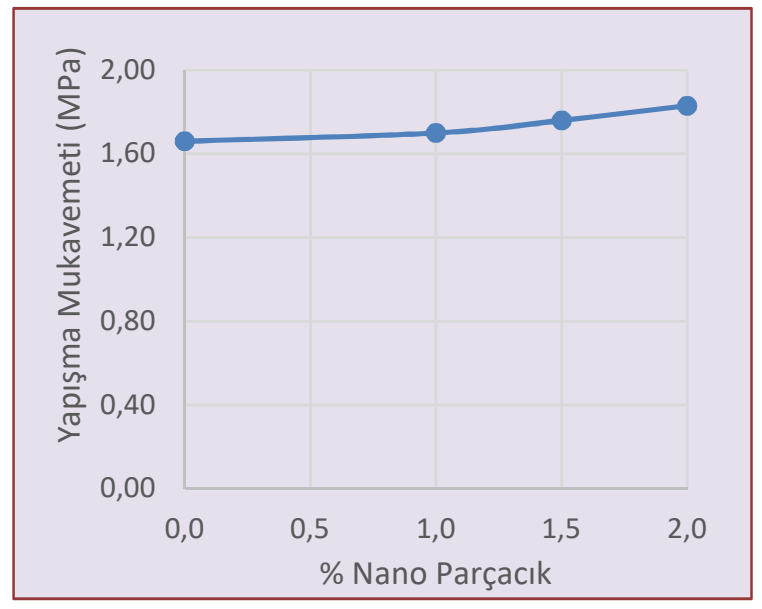

b)

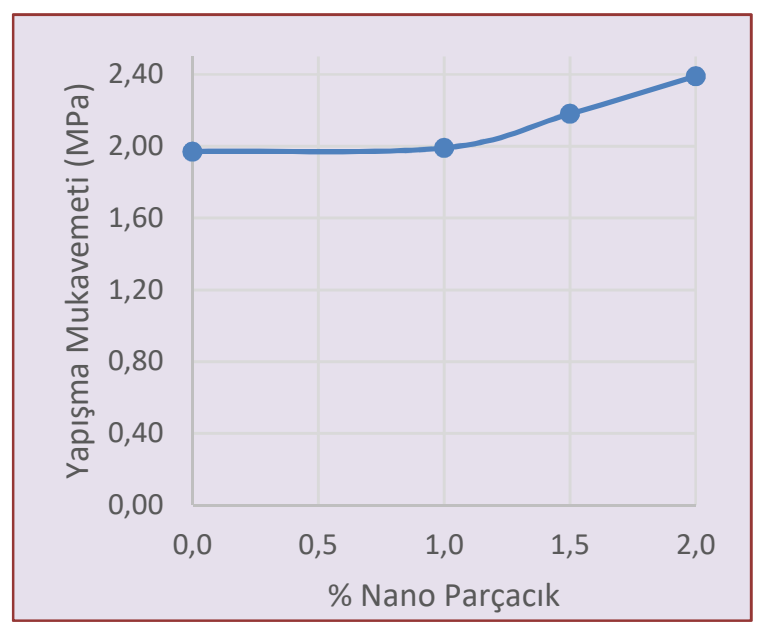

c)

Şekil 5. Farklı yüzey pürüzlülükleri için nanopartikül oranına bağlı olarak yapışma mukavemetinin değişimi

\section{Sonuçlar}

a) Zımparasız yüzey b) Zımparalanmış levha c) Zımparalanmış levha ve dolly

Yapılan çalışmada, her iki yüzeyin de parlak olduğu, sadece Al levhanın zımparalanması ve her iki yüzeyinde zımparalanması durumunda, farklı oranlarda çok duvarlı karbon nanotüp karıştırılmış çelik yapıştırıcısının yapışma mukavemeti incelenmiştir. Hem yüzey pürüzlülüğünün artırılması hem de nanoparçacık oranlarının \%2 oranında eklenmesiyle yapışma mukavemetinde $\% 57,2$ artış sağlandığ 1 tespit edilmiştir.

\section{Teşekkür}

Çalışmanın gerçekleştirilmesi için maddi destek veren Sivas Cumhuriyet Üniversitesi Bilimsel Araştırma Projeleri (CUBAP) Koordinatörlüğüne teşekkür ederiz (Proje No: TEKNO 008). 


\section{Kaynaklar}

[1] Aydın, S., Yapıştırıcı ile birleştirilmiş prizmatik geçmeli bağlantıların mekanik analizleri, Doktora Tezi, Fırat Üniversitesi Fen Bilimleri Enstitüsü Elazı̆̆ 2012.

[2] Hong-Yuan L, Gong-Tao W, Yiu-Wing M, Ying Z. 2011. On fracture toughness of nanoparticle modified epoxy. Composites: Part B 42 2011; 2170-2175.

[3] Chena H., Jacobs O., Wua W., Rudiger G. Schadel B., Effect of dispersion method on tribological properties of carbon nanotube reinforced epoxy resin composites. Polymer Testing 26 2007:351-360.

[4] Delale, F., Erdogan, F. and Aydınoglu, M.N., Stress in Adhesively Bonded Joints; Closed Form Solution, Journal of Composite Materials 1980; 15: 249-271.

[5] Sawyer, J.W., and Cooper, P.A., Analytical and Experimental Results for Bonded Single Lap, Joints With Performed Adherends, AIAA Journal 1981; 19/11:1443-1451.

[6] Apalak, M.K., and Davies, R., 1993. Ananlysis and Design of Adhesively Bonded Corner Joints, Int. J. Adhesion and Adhesives 1993; 13/4:219-235.

[7] Aydın, M.D., Özel, A. and Temiz, Ş., The effect of adherent thickness on the failure of adhesively bonded single-lap joints, J. Adhesion Sci. Technology, 2005; 19(8):705-718. 